\title{
COVID-19 Pandemic: Impact of Quarantine on Medical Students' Mental Wellbeing and Learning Behaviors
}

\author{
Sultan Ayoub $\mathrm{Meo}^{1}$, Abdulelah Adnan Abukhalaf ${ }^{2}$, \\ Ali Abdullah Alomar ${ }^{3}$, Kamran Sattar ${ }^{4}$, David C Klonoff ${ }^{5}$
}

\section{ABSTRACT}

Background and Objectives: The novel coronavirus COVID-19 pandemic causes great public health and socioeconomic harms. Worldwide many countries implemented quarantine policies to minimize the spread of this highly contagious disease. The present study aim was to investigate the impact of quarantine on the medical students' mental wellbeing and learning behaviors.

Methods: In this descriptive study, we used a questionnaire with a Five-Point Likert Scale to collect the information. The questionnaire was distributed among 625 medical students through their emails with a response rate of $530(84.8 \%)$, majority $294(55.47 \%)$ being female. The survey questionnaire consisted of total 20 items; 12 items were related to psychological wellbeing and stress-allied queries and 08 items were about learning behaviors.

Results: The findings encompass two important characteristics related to quarantine, psychological wellbeing, and learning behaviors. A combined cohort of 234 medical students, either female or male, (which was $44.1 \%$ of the total responders) showed a sense of being emotionally detached from family, friends and fellow students, 125/ 530 (23.5\%) medical students felt disheartened. Both female and male medical students showed a marked decrease in their overall work performance. Moreover, $56.2 \%$ of the total students $(61.5 \%$ of the females and $49.5 \%$ of the males) felt a decrease in the time they spent studying. Conclusions: Both female and male medical students have identified that quarantine has caused them to feel emotionally detached from family, fellows, and friends and decrease their overall work performance and study period. The findings also show that one-fourth of the medical students who participated in this study felt disheartened during the quarantine period. The long-term quarantine due to COVID-19 pandemic may causes further worsening in the psychological and learning behaviors of these medical students.

KEYWORDS: COVID 19, Quarantine, Mental Wellbeing, Learning Behaviors.

doi: https://doi.org/10.12669/pjms.36.COVID19-S4.2809

How to cite this:

Meo SA, Abukhalaf AA, Alomar AA, Sattar K, Klonoff DC. COVID-19 Pandemic: Impact of Quarantine on Medical Students' Mental Wellbeing and Learning Behaviors. Pak J Med Sci. 2020;36(COVID19-S4):S43-S48. doi: https://doi.org/10.12669/pjms.36.COVID19-S4.2809

This is an Open Access article distributed under the terms of the Creative Commons Attribution License (http://creativecommons.org/licenses/by/3.0), which permits unrestricted use, distribution, and reproduction in any medium, provided the original work is properly cited.

\section{INTRODUCTION}

The novel Severe Acute Respiratory Syndrome Coronavirus 2 (SARS-CoV-2) also called COVID-19 pandemic emerged from Wuhan, China, and has spread all over the world causing huge threats to human health and lives. ${ }^{1}$ The COVID-19 has diverse

Correspondence:

Prof. Sultan Ayoub Meo, MBBS, Ph.D, M Med Ed, FRCP (London, UK).

Department of Physiology, College of Medicine, King Saud University, PO Box 2925, Riyadh 11461. Saudi Arabia.

Email: sultanmeo@hotmail.com / smeo@ksu.edu.sa

* Received for Publication:

* Revision Received:

* Revision Accepted:
April 30, 2020

May 7, 2020

May 10, 2020 epidemiological and biological characteristics, making it more contagious than earlier pandemics such as SARS-CoV and MERS-CoV. ${ }^{2}$ The severe contagious nature of COVID-19 developed a unique threatening situation in the entire world. Globally approximately 3.9 billion people are quarantined in their homes. ${ }^{3}$

The quarantine or physical isolation polices are implemented by many countries to contain their people, minimize the spread of disease, and control the contamination of infection. The quarantine included short to medium-term lockdowns, voluntary home restriction, cancellation of social and public events, and travel restrictions. ${ }^{4}$

In COVID-19 pandemic, medical fraternity 
including physicians, nurses, paramedical staff and medical students are at high risk as they are performing their duties in hospitals, causing increased stress ${ }^{5}$ in these unprepared situations. ${ }^{6}$ The current quarantine conditions have shut down schools and universities and have suspended face-to-face teaching and learning sessions. This has affected the physiological phases of lives, and induced many individual and collective health, socioeconomic, psychological and educational concerns. The aim of the present study was to investigate the impact of two weeks quarantine on medical students' mental wellbeing and learning behaviors during this period of social isolation.

\section{METHODS}

Study design and settings: The present questionnaire based observational study was conducted in the Department of Physiology, College of Medicine, King Saud University during the period April 2020. Selection of the students: The details of the medical students, including names, addresses, phone numbers, email addresses age, gender and levels of the medical school education was obtained from the Vice Dean Office and student council, College of Medicine, King Saud University, Riyadh. The selection of students was random, and student's information was kept confidential. We employed a power formula to calculate the sample size. ${ }^{7}$ The sample size was obtained by using simple random sampling. In this study, undergraduate medical students were invited to participate from medical school of King Saud University, Riyadh, Saudi Arabia.

Questionnaire: The questionnaire was designed based on the information taken from earlier studies and edited to suit the objectives. ${ }^{5,8}$ A pilot study was conducted to test the validity of the questionnaire. The final version of the questionnaire contained 20 questions divided into three main parts. The first part was about demographic features; the second was designed to assess psychological wellbeing and the third section was based on learning behaviour queries.

Online questionnaires were distributed among the medical students through emails to collect the required information. We used a questionnaire with Five Point Likert Scale to collect the information. The Five Point Likert Scale is a well-known and highly accepted scale that can help to assess the qualitative magnitude of targeted outcomes. ${ }^{9,10}$

The survey included an opening page for informed consent and an opening paragraph that asks whether or not they agree to participate in the study. The participants were given the option to choose whether to participate or not by clicking on the box corresponding to their responses. Students who opted to participate were led to a series of questions. No reward of any kind was given to the participants. The collected information was kept completely confidential. The electronic questionnaire was distributed among the 625 medical students through their emails, and 530 (84.8\%) of the medical students responded. Thus, the total number of participants was 530, and out of this total, 294 (55.47\%) were female and 236 (44.53\%) male.

Statistical Analysis: The findings were analyzed by using (SPSS) software version 22.0 for Microsoft windows. The numbers and percentages were calculated. A p-value $<0.05$ was considered to be significant.

Ethical Considerations: Ethical approval was obtained from the Institutional Review Board, College of Medicine, King Saud University, Riyadh, Saudi Arabia (Ref \#: 20/0308/IRB).

\section{RESULTS}

The survey questionnaire was distributed among the 625 medical students through their emails. The total number of participants who responded were $530(84.8 \%) ; 294(55.47 \%)$ were female and $236(44.53$ $\%)$ were male. The mean age for females was 21.2 years, and for males was 22.56 years (Table-I). The survey questionnaire consisted of total 20 items; 12

Table-I: Medical students anthropometric characteristics

\begin{tabular}{|c|c|}
\hline $\begin{array}{l}\text { Sociodemographic } \\
\text { Characteristics }\end{array}$ & $\begin{array}{c}\text { Number } \\
\text { and Percentage }\end{array}$ \\
\hline \multicolumn{2}{|c|}{ Gender } \\
\hline Male & $236(44.52 \%)$ \\
\hline Female & $294(55.48 \%)$ \\
\hline \multicolumn{2}{|c|}{ Age (Year) } \\
\hline Male & $22.56 \pm 1.64$ year \\
\hline Female & $21.2 \pm 1.59$ year \\
\hline \multicolumn{2}{|c|}{ Marital Status } \\
\hline Single & $522(98.50 \%)$ \\
\hline Married & $08(1.50 \%)$ \\
\hline \multicolumn{2}{|c|}{ Level of study (College year) } \\
\hline Year 1 & $40(7.54 \%)$ \\
\hline Year 2 & $112(21.13 \%)$ \\
\hline Year 3 & $91(17.16 \%)$ \\
\hline Year 4 & $71(13.39 \%)$ \\
\hline Year 5 & $216(40.75 \%)$ \\
\hline
\end{tabular}


COVID-19 and Quarantine.

Table-II: Medical students feedback about stress allied queries $(n=530)$.

\begin{tabular}{|c|c|c|c|c|c|c|c|}
\hline \multirow[t]{2}{*}{ Survey statement } & \multicolumn{2}{|c|}{ Strongly agree E Agree } & \multicolumn{2}{|c|}{ Neutral } & \multicolumn{2}{|c|}{ trongly disagree $\mathcal{E}$ Disagree } & \multirow[t]{2}{*}{ Parametric P-value } \\
\hline & Female & Male & Female & Male & Female & Male & \\
\hline \multicolumn{8}{|c|}{ Do you have frequent thoughts of being infected during this pandemic? } \\
\hline & $98(33.33)$ & $43(18.22)$ & $96(32.65)$ & $57(24.15)$ & $100(34.01)$ & $136(57.63)$ & $<.001$ \\
\hline \multicolumn{8}{|c|}{ Have you felt depressed during this quarantine? } \\
\hline & $66(22.45)$ & $59(25)$ & $62(21.09)$ & $69(29.24)$ & $166(56.46)$ & $108(45.76)$ & 0.034 \\
\hline \multicolumn{8}{|c|}{ Have you felt hopeless, exhausted or emotionally unresponsive during this quarantine? } \\
\hline & $116(39.46)$ & $86(36.44)$ & $40(13.61)$ & $43(18.22)$ & $138(46.94)$ & $107(45.34)$ & 0.339 \\
\hline \multicolumn{8}{|c|}{ Have you noticed a reduction in your awareness or feeling of being confused? } \\
\hline & $103(35.03)$ & $85(36.02)$ & $51(17.35)$ & $65(27.54)$ & $140(47.62)$ & $86(36.44)$ & 0.006 \\
\hline \multicolumn{8}{|c|}{ Have you felt a sense of being emotionally detached from family, friends, etc.? } \\
\hline & $127(43.2)$ & $107(45.34)$ & $64(21.77)$ & $53(22.46)$ & $103(35.03)$ & $76(32.2)$ & 0.789 \\
\hline \multicolumn{8}{|c|}{ Did you invest more time on reading or watching COVID-19 related information? } \\
\hline & $113(38.44)$ & $47(19.92)$ & $76(25.85)$ & $81(34.32)$ & $105(35.71)$ & $108(45.76)$ & 0.001 \\
\hline \multicolumn{8}{|c|}{ Do you have anxiety dealing with febrile patients? } \\
\hline & $78(26.53)$ & $89(37.71)$ & $109(37.07)$ & $72(30.51)$ & $107(36.39)$ & $75(31.78)$ & 0.022 \\
\hline \multicolumn{8}{|c|}{ Have you been anxious or having insomnia during this quarantine? } \\
\hline & $127(43.2)$ & $79(33.47)$ & $47(15.99)$ & $37(15.68)$ & $120(40.82)$ & $120(50.85)$ & 0.047 \\
\hline \multicolumn{8}{|c|}{ Have you had episodes of indecisiveness or poor concentration during this quarantine? } \\
\hline & $132(44.9)$ & $80(33.9)$ & $55(18.71)$ & $41(17.37)$ & $107(36.39)$ & $115(48.73)$ & 0.012 \\
\hline \multicolumn{6}{|c|}{ Have you been afraid of going home because there is a possibility of infecting your family? } & $\begin{array}{l}\text { family? } \\
\quad 85(36.02)\end{array}$ & 0.027 \\
\hline \multicolumn{8}{|c|}{ Are you having a lack of motor coordination? } \\
\hline \multicolumn{8}{|c|}{ Are you feeling a slowness in execution of movement? } \\
\hline
\end{tabular}

items were related to psychological wellbeing allied queries and 08 items were on learning behaviors.

Table-II shows twelve stress allied responses were enquired from the medical students. TableII. One hundred twenty seven (43.2\%) female and 107 (45.34\%) male strongly agreed for "a sense of being emotionally detached from family, fellows and friends". The combined percentage of these students was 234 (44.15\%). While enquiring about "depressed during this quarantine period" 66 $(22.45 \%)$ female and 59 (25.00\%) male, about one fourth of the total number medical students felt depressed during the quarantine period of two weeks (Table-II).

While inquiring about "feelings of hopeless, exhausted or emotionally unresponsive during this quarantine period" 116 (39.46) female and $86(36.44 \%)$ male agreed that they felt hopeless, exhausted, or emotionally unresponsive during the quarantine period. The total number of these students was 202 (38.11\%).

A total of 08 items related to the quarantine impact on students' learning behaviors used are shown in Table-III. 165 (56.12\%) of the females, and $103(43.64 \%)$ of the males strongly agreed with a statement describing "deterioration in work performance and studying subjects contents." It was noted that $181(61.56 \%)$ of the females and 117 $(49.58 \%)$ the males had experienced "decreased in overall study period". The combined percentage of students who felt that their study period was decreased was 298 (56.22\%). While enquiring about "concentrating on the studies" 83 (28.23\%), of the female medical students and 89 (37.71\%) of the male students having difficulty in performing mental calculations (Table-III).

\section{DISCUSSION}

Health is a state of physical, mental, and social wellbeing and not merely the absence of disease or infirmity. ${ }^{11}$ Human health and wellbeing are discretely rooted in being surrounded by a functioning society. The COVID-19 outbreak has induced a global public and mental health crisis as well as a huge psycho-social experiment. We have noticed that quarantine due to the COVID-19 
Sultan Ayoub Meo et al.

Table-III: Medical student's feedback on the impact of quarantine on students' learning behaviors $(\mathrm{n}=530)$.

\begin{tabular}{|c|c|c|c|c|c|c|c|}
\hline \multirow[t]{2}{*}{ Survey statement } & \multicolumn{2}{|c|}{ Strongly agree and Agree } & \multicolumn{2}{|c|}{ Neutral } & \multicolumn{2}{|c|}{ Strongly disagree and Disagree } & \multirow[t]{2}{*}{ Parametric P-value } \\
\hline & Female & Male & Female & Male & Female & Male & \\
\hline \multicolumn{8}{|c|}{ Have you noticed deterioration in your work performance/studying? } \\
\hline & $165(56.12)$ & $103(43.64)$ & $45(15.31)$ & $47(19.92)$ & $84(28.57)$ & $86(36.44)$ & 0.017 \\
\hline \multicolumn{8}{|c|}{ Do you remember your subject's contents appropriately? } \\
\hline & $69(23.47)$ & $94(39.83)$ & $140(47.62)$ & $91(38.56)$ & $85(28.91)$ & $51(21.61)$ & .001 \\
\hline \multicolumn{8}{|c|}{ Are you appropriately concentrating on your studies? } \\
\hline & $83(28.23)$ & $89(37.71)$ & $90(30.61)$ & $40(16.95)$ & $121(41.16)$ & $107(45.34)$ & .001 \\
\hline \multicolumn{8}{|c|}{ Are you having a difficulty in performing two tasks simultaneously } \\
\hline & $134(45.58)$ & $61(25.85)$ & $59(20.07)$ & $98(41.53)$ & $101(34.35)$ & $77(32.63)$ & .001 \\
\hline \multicolumn{8}{|c|}{ Are you having difficulty in performing mental calculations? } \\
\hline & $63(21.43)$ & $43(18.22)$ & $76(25.85)$ & $48(20.34)$ & $155(52.72)$ & $145(61.44)$ & 0.127 \\
\hline \multicolumn{8}{|c|}{ Are you having difficulty in recalling recent information? } \\
\hline & $92(31.29)$ & $48(20.34)$ & $54(18.37)$ & $60(25.42)$ & $148(50.34)$ & $128(54.24)$ & 0.009 \\
\hline \multicolumn{8}{|c|}{ Are you having difficulty in recalling old information? } \\
\hline & $91(30.95)$ & $37(15.68)$ & $78(26.53)$ & $95(40.25)$ & $125(42.52)$ & $104(44.07)$ & $<.001$ \\
\hline \multicolumn{8}{|c|}{ Are the hours of study increased or decreased? } \\
\hline & Љ181 (61.56) & 仓117 (49.58) & $\begin{array}{l}51(17.35) \\
\text { Same }\end{array}$ & $\begin{array}{c}47 \text { (19.92) } \\
\text { Same }\end{array}$ & 62 (21.09) & $72(30.51)$ & 0.015 \\
\hline
\end{tabular}

pandemic has caused stress and changes in the learning behaviors of medical students. Both male and female participants exhibited deterioration in their study and work performance.

With the current worldwide trend of quarantine and isolation due to Covid-19, this deterioration in mood seems to have occurred sooner than one might have expected. Hawryluck et $\mathrm{al}^{5}$ conducted a study on psychological effects of quarantine, and reported that quarantined persons exhibited a high prevalence of psychological distress: posttraumatic stress disorder (28.9\%) and depression (31.2\%).

The world has witnessed that because of the coronavirus disease outbreak in December 2019 many countries have been asking their residents to isolate themselves at home or in quarantine premises. For example, authorities in the Kingdom of Saudi Arabia reacted to the pandemic as a responsible nation, and on March 25, 2020 decided to enact a lock-down on capital city Riyadh as a part of the fight against Covid-19 outbreak. On Thursday, 26 March, the Saudi authorities imposed a total lockdown in the city Riyadh, along with Makkah and Medina, Islam's two holiest cities, as part of tighter constraints to counter the virus. During the current COVID-19 pandemic, with the current lockdown situation, medical students in Saudi Arabia are living in a quarantine inside their residence facilities.

More recently, Röhr et al., ${ }^{12}$ has demonstrated that quarantine measures during COVID-19 outbreaks have severe negative consequences for mental health. In another study, Lei et al., ${ }^{13}$ identified high prevalence of anxiety and depression among people who quarantined during COVID-19 outbreak in southwestern China. Similarly in the present study, we found that $125(23.5 \%)$ medical students felt disheartened and depressed. The most probable reasons for negative consequences for mental health during quarantine are that people considered it an unpleasant experience, because of having to depart from fellows, friends and family, losing the ability to move about freely, experiencing doubts about the spread of disease, and developing intense feelings and reactions.

The quarantine phase is a complex intervention within the jurisdiction of public health. ${ }^{14}$ Our results demonstrate two important characteristics related to the COVID-19 quarantine, namely an increase in stress and an increase in dysfunctional learning behaviors. Although, medical students believe that quarantine has not much affected their learning and psychological wellbeing, the students whom we interviewed stated that quarantine has caused them to feel emotionally detached from family, fellows and friends, and has led to a decrease in overall work performance and duration of study.

In the past, the quarantine compliance rate has been positive, studies have indicated high levels of acceptance of quarantine among samples of Toronto-area residents (97\%) and US citizens (93\%) during a SARS 1 pandemic quarantine. ${ }^{15,16}$ In the 
current study, a good number of responses were also recorded where participants have a difference of opinion. The female and male medical students showed a sense of being emotionally detached from family, fellow professionals and friends, feel depressed and decreased in their overall study work performance and study period.

The literature had consistently reported differences occurring concerning stress among males and females. This is constant with preceding research indicating that female physicians are more likely to be emotionally fatigued at the commencement of exhaustion, compared to male physicians. ${ }^{17}$ Similarly, female students in the present study were found to be motivated in handling their learning, especially when it came to performing two tasks simultaneously. Brooks et al., ${ }^{18}$ reported negative psychological effects including post-traumatic stress symptoms, confusion, and anger due to the COVID-19 outbreak quarantine. The authors concluded that during a long duration quarantine, fear, frustration, inadequate information and financial loss are the main causes of negative psychological impact. Similarly, the present study findings suggest that the reported alterations in attitude and mood may be due to the threatening situation of the COVID-19 pandemic. Medical students, in particular, may feel differently once this situation is over, and explicit research should explore such differences.

\section{CONCLUSION}

Both female and male medical students have identified that quarantine has caused them to feel emotionally detached from family, fellows, and friends, and has decreased their overall work performance and study period. The findings also show that one fourth of the medical students who participated in this study felt depressed during the quarantine period of two weeks. The longterm quarantine due to COVID-19 pandemics may cause further worsening in the psychological and learning behaviors of these medical students. The results from this study might provide to health policymakers evidence about the psychological and emotional influences of quarantine on medical students so that they might produce an important guideline for managing the medical students' quarantine. Indeed, we believe that the current results indicate the need for supplementary mental wellbeing interventions for everyone while they are quarantined. This goal could be achieved by using a healthy diet, exercise at home, proper sleep and engaging in healthy physical, intellectual and educational activities. In situations where quarantine is deemed necessary, the policy makers should quarantine individuals for no longer than a required period.

Acknowledgments: Thankful to the "Deanship of Scientific Research, King Saud University, Riyadh, Saudi Arabia for supporting the work through research group project (RGP-VPP 181)".

Conflicts of Interest: Authors declare no conflict of interest.

\section{REFERENCES}

1. Meo SA, Alhowikan AM, Al-Khlaiwi T, Meo IM, Halepoto DM, Iqbal M, et al. Novel coronavirus 2019nCoV: prevalence, biological and clinical characteristics comparison with SARS-CoV and MERS-CoV. Eur Rev Med Pharmacol Sci. 2020;24(4):2012-2019. doi: 10.26355/ eurrev_202002_20379

2. Meo SA, Al-Khlaiwi T, Usmani AM, Meo AS, Klonoff DC, Hoang TD. Biological and Epidemiological Trends in the Prevalence and Mortality due to Outbreaks of Novel Coronavirus COVID-19. J King Saud Univ Sci. 2020. doi: 10.1016/j.jksus.2020.04.004.

3. 3.9 billion people are currently called on to stay in their home. Available at: https://www.dailymail.co.uk/news/ article-8181001/3-9-billion-people-currently-called-stayhomes-coronavirus.html. Cited date April 26, 2020.

4. Usher K, Bhullar N, Jackson D. Life in the pandemic: Social isolation and mental health. J Clin Nurs. 2020. doi: 10.1111/ jocn.15290

5. Hawryluck L, Gold WL, Robinson S, Pogorski S, Galea S, Styra R. SARS control and psychological effects of quarantine, Toronto, Canada. Emerg Infect Dis. 2004;10 (7):1206-1212. doi: 10.3201/eid1007.030703.

6. Urooj U, Ansari A, Siraj A, Khan S, Tariq H. Expectations, Fears and Perceptions of doctors during Covid-19Pandemic. Pak J Med Sci. 2020;36(COVID19-S4). doi: 10.12669/pjms.36. COVID19-S4.2643

7. Jones SR, Carley S, Harrison M. An introduction to power and sample size estimation. Emerg Med J. 2003;20(5):453458. doi: $10.1136 /$ emj.20.5.453

8. Reynolds DL, Garay JR, Deamond SL, Moran MK, Gold W, Styra R.Understanding, compliance and psychological impact of the SARS quarantine experience. Epidemiol Infect. 2008;136(7):997-1007.

9. Zante B, Hautz W, Schefold JC. Physiology education for intensive care medicine residents: A 15-minute interactive peer-led flipped classroom session. PLoS One. 2020;15(1):e0228257. doi: 10.1371/journal.pone.0228257

10. Ellis S, Purkiss J, Abdoler E, Opaskar A, Mangrulkar RS, Kolars JC, et al. Variability in student perceptions of mistreatment. Clin Teach. 2019;16(2):142-146.

11. World Health Organization. Mental health: a state of wellbeing. 2014. Available online at: http://www.who.int/ features/factfiles/mental_health/en/ Cited date April 12, 2020.

12. Röhr S, Müller F, Jung F, Apfelbacher C, Seidler A, RiedelHeller SG. Psychosocial Impact of Quarantine Measures During Serious Coronavirus Outbreaks: A Rapid Review. Psychiatr Prax. 2020;47(4):179-189. doi: 10.1055/a-1159-5562 
13. Lei L, Huang X, Zhang S, Yang J, Yang L, Xu M. Comparison of Prevalence and Associated Factors of Anxiety and Depression Among People Affected by versus People Unaffected by Quarantine During the COVID-19 Epidemic in Southwestern China. Med Sci Monit. 2020;26:e924609. doi: 10.12659/MSM.924609

14. Barbisch D, Koenig KL, Shih FY. Is there a case for quarantine? Perspectives from SARS to Ebola. Disaster Med Public Health Prep. 2015;9:547-553.

15. Blendon RJ, Benson JM, DesRoches CM, Raleigh E, TaylorClark K. The public's response to severe acute respiratory syndrome in Toronto and the United States. Clin Infect Dis. 2004:38:925-931.

16. Svoboda T, Henry B, Shulman L, Kennedy E, Rea E, Ng W. Public health measures to control the spread of the severe acute respiratory syndrome during the outbreak in Toronto. N Engl J Med. 2004;350:2352-2361.

17. Houkes I, Winants Y, Twellaar. Development of burnout over time and the causal order of the three dimensions of burnout among male and female GPs. A Three-Wave Panel Study. BMC Public Health. 2011;11(1):240.
18. Brooks SK, Webster RK, Smith LE, Woodland L, Wessel $\mathrm{S}$, Greenberg $\mathrm{N}$, et al. The psychological impact of quarantine and how to reduce it: rapid review of the evidence. Lancet. 2020;395(10227):912-920. doi: 10.1016/ S0140-6736(20)30460-8

\section{Authors' Contributions:}

SAM: Research conceptualization, supervision, manuscript writing.

AAA, AAA, KS, Methodology, literature review, data collection and data analysis.

DCK: Manuscript writing. All authors have read and agreed to the published version of the manuscript.

1. Sultan Ayoub Meo

Department of Physiology, College of Medicine,

2. Abdulelah Adnan Abukhalaf

Department of Physiology, College of Medicine,

3. Ali Abdullah Alomar

Department of Physiology, College of Medicine,

4. Kamran Sattar

Department of Medical Education, College of Medicine,

5. David C Klonoff

Diabetes Research Institute,

Mills-Peninsula Medical Center San Mateo, California, USA.

1-4: King Saud University, Riyadh, Saudi Arabia. 